\title{
Automatic detection method, forecast and alert of solar proton events
}

\author{
Ganghua Lin \\ Key Laboratory of Solar Activity, National Astronomical Observatories, \\ Chinese Academy of Sciences, \\ Datun Rd. 20A, Chaoyang District, Beijing, 100012, China \\ email: lgh@bao.ac.cn
}

\begin{abstract}
The methods of automatic solar active phenomenon or event detection have been researched and explored by people for many years, which have gone into actual services. The paper analyzes the relationship between these methods of automatic detection and the forecast or alert, using the solar short-term proton events predictions as an example. Using automatic method to conduct forecast or alert is under thinking.
\end{abstract}

Keywords. Sun: activity, particle emission, magnetic fields, solar-terrestrial relations; methods: data analysis, statistical

\section{Introduction}

The forecasts and alerts of space environment for live of human being, development of society and aerospace profession are vital and necessary. At the same time, the automatic detection methods have characteristics of reliability and rapidity. With the growing demand for forecasts of solar activity, there is great need for these methods. In the past many years, methods of automatic solar active phenomenon or event detection have been researched and explored by people, and gone into actual service. That whether these methods can be used systematically in the forecasts and alerts of space environment or not has a preliminary analysis in the paper.

\section{Forecast or alert factors}

The forecast is to predict solar event or phenomenon that is going to occur several days later. The alert is to warn an event that is going to occur in dozes of minutes or dozes of hours. They have both similarities and differences. To facilitate the further analysis, table 1 presents the forecast or alert factors of proton event that are frequently used, the obtained method and the automatic detection method. In Table 1, the forecast factors are main clues of propagation process of proton and potential factors of occurrence of the proton event; the obtained method refers to the observing equipments by which the factors can be obtained; the automatic detection method refers to the explored method that is used for detecting the corresponding phenomenon or event.

In the proton event forecast system, the main factors can be roughly separated into four category wang 1999 .

Among them, sunspots related factors are : Zürch classification and area of sunspot groups, magnetic classification and magnetic density of sunspot groups, McIntosh classification, special sunspot groups and transverse field structure, sunspot volution structure and movement, alternation of the area of sunspot groups 3 days before the explosion of flare event. 
Table 1. Forecast or alert factors of solar proton event.

\begin{tabular}{|c|c|c|}
\hline Forecast or alert factors & Obtained method & $\begin{array}{l}\text { Automatic detection } \\
\text { method }\end{array}$ \\
\hline Soft x-ray flare or Halpha flare & X-ray or full disk Ha telescope & $\begin{array}{l}\text { explored. } \\
\text { Ming et al. (2003) }\end{array}$ \\
\hline sunspot: & & $\begin{array}{l}\text { explored. } \\
\text { Curto et al. }(2008), \\
\text { Benkhalil et al. }(2006) \text {, } \\
\text { Ming et al. }(2003)\end{array}$ \\
\hline 1 The McIntosh classification & $\begin{array}{l}1 \text { The first McIntosh parameter } \mathrm{z} \text {, } \\
\text { the second McIntosh parameter } \mathrm{p} \text {, } \\
\text { the third McIntosh parameter c. }\end{array}$ & \\
\hline 2 The magnetic classification & $\begin{array}{l}2 \text { SOHO MDI } 6767 \AA \text { magnetograms, } \\
\text { CaII } 8542 \AA \text { magnetogram( Kitt Peak), } \\
\text { the FeI line magnetogram (Mt Wilson). }\end{array}$ & \\
\hline 3 The recent flaring activity & $\begin{array}{l}3 \text { The recent X-ray flares observed on GOES, } \\
\text { event lists and the current movies of } \\
\text { SOHO EIT FeXII } 195 \AA\end{array}$ & \\
\hline $\begin{array}{l}4 \text { The level of flaring activity } \\
5 \text { Special magnetic classification } \\
\text { of sunspot group }\end{array}$ & 4 The X-ray background level on GOES. & \\
\hline $10.7 \mathrm{~cm}$ radio $\mathrm{flux}$ & $\begin{array}{l}10.7 \mathrm{~cm} \text { radio flux at frequency } 2800 \mathrm{MHz} \\
2695 \mathrm{MHz} \text { is an alternative. The latest SOHO } \\
\text { MDI continuum or Catania observation }\end{array}$ & downloading \\
\hline Proton event of impulse type & $\begin{array}{l}\text { It is corresponding to type III and } \mathrm{V} \text { of } \\
\text { radio eruption. STEREO }\end{array}$ & \\
\hline $\begin{array}{l}\text { Proton event of progression } \\
\text { type(be rich in proton) }\end{array}$ & $\begin{array}{l}\text { It is corresponding to type II and IV of } \\
\text { radio eruption. STEREO }\end{array}$ & \\
\hline Frequency of flare activity & & $\begin{array}{l}\text { explored. } \\
\text { Ming et al. (2003), } \\
\text { improvable output }\end{array}$ \\
\hline $\begin{array}{l}\text { CME-driven interplanetary } \\
\text { shock waves }\end{array}$ & $\begin{array}{l}\text { LASCO, STEREO, EIT FeXII } 195 \AA \text {, } \\
\text { the list of radio bursts prepared by SEC } \\
\text { or/and the latest Culgoora PRESTO message. }\end{array}$ & \\
\hline Coronal magnetic field & $\begin{array}{l}\text { LASCO, EIT } 284 \AA \text {, TRACE } 195 \AA \\
\text { fulldisk GOES/SXI, } \\
\text { SOHO/MDI(NSO/KPVT), STEREO }\end{array}$ & \\
\hline Interplanetary magnetic field & $\begin{array}{l}\text { ACE, the CELIAS/MTOF/PM sensor on } \\
\text { the SOHO spacecraft }\end{array}$ & \\
\hline $\begin{array}{l}\text { Flux density of proton. } \\
\text { The distance between the flaring } \\
\text { region and root segment region of } \\
\text { open magnetic field line in the } \\
\text { interplanetary. }\end{array}$ & $\begin{array}{l}\text { GOES } 11 \\
\text { STEREO }\end{array}$ & downloading \\
\hline $\begin{array}{l}\text { Solar disk location of flare } \\
\text { eruption }\end{array}$ & & $\begin{array}{l}\text { Explored. } \\
\text { Ming Qu, et al. (2003) }\end{array}$ \\
\hline Proton peak flux levels & GOES11 & downloading \\
\hline
\end{tabular}

Active area related factors are: the shape of magnetic neutral line, magnetic flux emerge and longitudinal field gradient, flare activities frequency, similarity between current active area and old proton active area.

The location related factors are: the location of flaring on the solar disk, reproducibility between active region longitude and proton flare, the active area and the foot points of line of magnetic connection of solar-terrestrial are at the same magnetic polarity area, the active area and disk center locate at the same magnetic polarity area, active area and foot points on disk of line of magnetic connection of solar-terrestrial are in the same sector area of interplanetary magnetic field. 


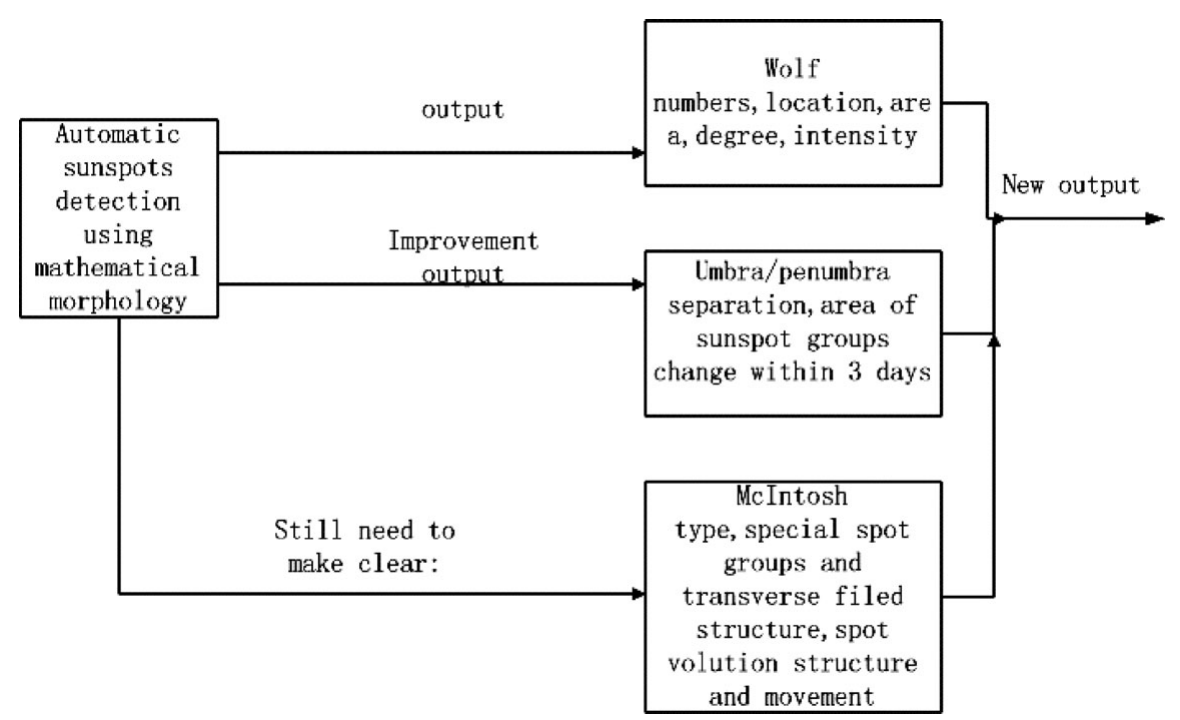

Figure 1. Sunspots automatic detecting and related forecast factors.

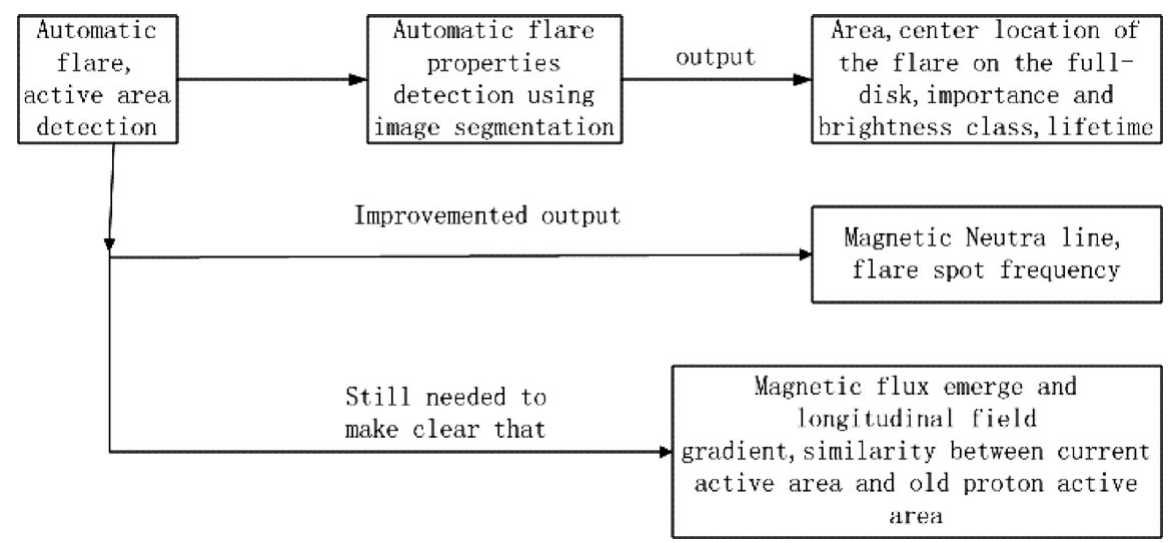

Figure 2. Active area automatic detecting and related forecast factors.

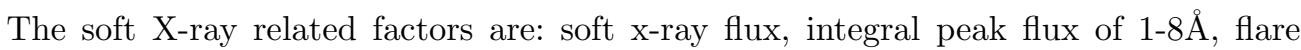
duration time of $\mathrm{x}$-ray.

\section{Method of automatic detecting and forecasts or alerts of flare proton event}

The flare proton event has been introduced. We build relationship between the methods of automatic detecting on solar events or phenomenons and their forecasts or alerts. Figure 1 presents possible output and possible output after improvement by means of automatic detection. Some factors may need to be made clear by further human interference. Figures 2 and 3 have similar structures and meanings.

\section{Discussion}

From Figures 1-4 we can see that half of all the factors can be automatically detected. Sixty percents of them can be automatically gained after the improvement. One third of 


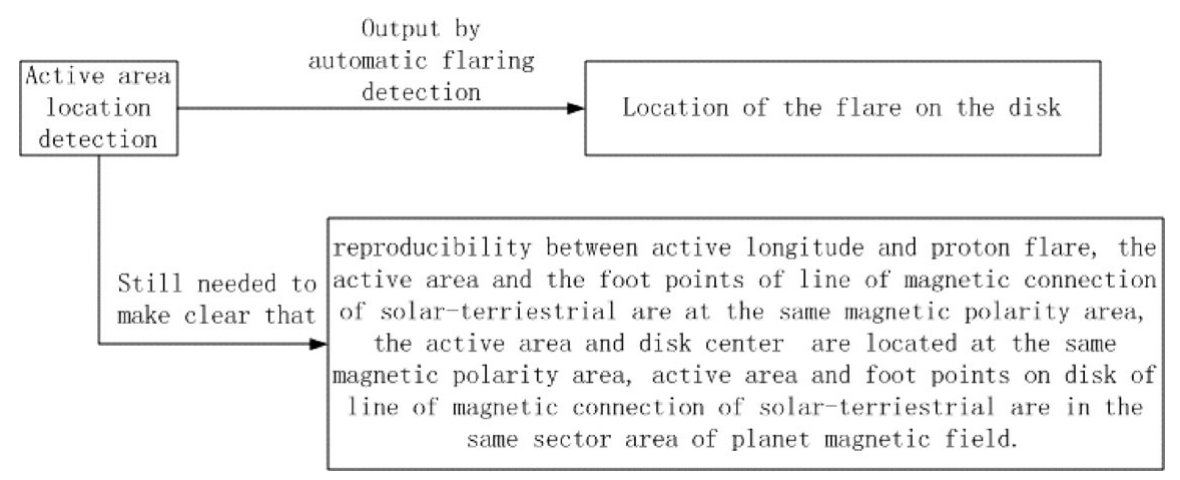

Figure 3. Active area location detecting and related forecast factors.

\begin{tabular}{|c|c|}
\hline \multirow{2}{*}{$\begin{array}{c}\text { Soft } x \text {-ray } \\
\text { detection }\end{array}$} & $\longrightarrow \begin{array}{c}\text { flux data from the list from SWPC FTP site, } \\
1-8 \AA \text { flux data from NGDC web site, flare } \\
\text { durationtime data from NGDC FTP site }\end{array}$ \\
\hline
\end{tabular}

Figure 4. X-ray detecting and related forecast factors.

the remains still need to be make clearer. We can find that some factors of the one third can be automatically obtained by downloading data, computed, others still need to be further analyzed by human.

I thank the editor for his careful and earnest. The work is supported by National Natural Science Foundation of China under grants 60673158.

\section{References}

Benkhalil, A., Zharkova, V. V., Zharkov, S., \& Ipson, S. 2006, Solar Phys., 235:87-106

Curto, J. J., Blanca, M., \& Martinez, E. 2008, Solar Phys., 250:411-429

Ming Qu, Frank Y. Shih, Ju Jing, \& Haimin Wang 2003, Solar Phys, 217:157-172

Wang Jialong 1999, Chinese Journal of Astronomy and Astrophysics, 19, 4, 412:418 